\title{
Travel Risks for Those With Serious Mental Illness
}

\author{
Mary V. Seeman* \\ Department of Psychiatry, University of Toronto, Toronto, Canada
}

Corresponding Author: Mary V. Seeman, MD, Professor Emerita, Department of Psychiatry, University of Toronto, Toronto, Canada. Email: Mary.Seeman@utoronto.ca

Received March 26, 2016; Accepted April 18, 2016; Online Published September 25, 2016

\begin{abstract}
Introduction: It has been known for a long time in the French-speaking, but not the English-speaking literature that travel can exacerbate pre-existing psychosis. The purpose of this article was to review the literature on this subject and present recommendations for prevention.

Methods: For this narrative review of the literature on travel risks in individuals with pre-existing psychosis, appropriate terms were used to search Google Scholar, and all identified English, French, and Polish references were investigated.

Results: Potential psychotogenic stresses of travel were found to be: mental confusion due to rapid transition into unfamiliar roles, physical discomfort and malaise seeding delusional beliefs, reawakening of old fears, loss of usual supports, overuse of substances to quiet fears, irregular scheduling or interruption of medications, jet lag with insomnia and hormonal shifts, the shock of acculturation, and unaccustomed interpersonal encounters. Women and the elderly were at greatest risk for symptom escalation related to travel.

Conclusion: Travel risks need to be recognized and anticipated in vulnerable populations because many travel stressors are preventable.

Keywords: Psychosis, Travel, Stress, Jet Lag
\end{abstract}

Citation: Seeman MV. Travel risks for those with serious mental illness. Int J Travel Med Glob Health. 2016;4(3):76-81. doi:10.20286/ijtmgh-040302.

\section{Introduction}

Long distance travel has long been known to aggravate pre-existing psychosis. ${ }^{1}$ Since at least the 1950s, reports have surfaced of travelers with psychiatric illness suffering travel-related psychotic decompensation, ${ }^{2,3}$ during air travel especially. According to the World Health Organization (WHO), mental illness is 1 of the 3 main health complications associated with air travel. ${ }^{4}$ Of all mental health problems encountered in travel, acute psychotic episodes constitute about one-fifth. ${ }^{5,6}$

Travel can be a destabilizing life event ${ }^{7}$ with many potential hazards to mental health, ${ }^{8}$ from the effects of drugs used for prophylaxis against infection, to homesickness, to disrupted circadian rhythms, to culture shock. Travel is especially destabilizing to people who are not used to being far from home, and who are, because of past illness, or cognitive problems, or other risk factors, vulnerable to psychosis. The longer and the further from home travel takes you, the higher the risk appears to be. The initial decision to leave home may already signal the beginning of psychotic thinking e.g., imaginary voices commanding a special undertaking, ${ }^{9}$ and the many ordeals of travel may, in fact, act as aggravators rather than as triggers. This article reviews the literature on travelassociated risks for individuals with a history of psychotic illness and presents recommendations for prevention.

\begin{abstract}
Methods
The strategy used to create this narrative review began with an examination of the 47 references cited in a recent paper in French on travel and psychotic disorders by Vermersch and colleagues. ${ }^{6}$ The multidisciplinary Google Scholar database was then further searched using the terms stress, attachment and travel + psychosis; insomnia, jet lag, and circadian rhythms + psychosis; travel + delusion. All qualitative and quantitative studies and reviews in English, French, and Polish were included unless they repeated previously included information. This narrative review aimed for breadth of information; no attempt was made to assess the quality of information sources. Twenty-four pertinent new papers were found, in addition to the original 47. Clinical examples from the women's clinic for psychosis in which the author practices ${ }^{10}$ are used to illustrate commonly described travel problems.
\end{abstract}

\section{Results \\ Starting off \\ Some people suffering from mental illness are attracted to airports and train stations even when they have no intention to travel. For the homeless, for instance, such sites provide shelter and 24-hour access to food, heat, plumbing, and anonymity. ${ }^{11}$ This is perhaps why behavior associated with psychosis (e.g.,}


erratic wandering, loud speech with no obvious addressee, emotional outbursts) is frequently seen in airports. The draw of airports and rail stations may be that they represent the pain of interpersonal separations as well as the hope of potential reunions. ${ }^{12}$ For someone starting out on a trip, the crowds, hubbub, and general arousal of the airport experience initiate a chain of uncertainty and bewilderment that can culminate in psychosis. ${ }^{13}$ For individuals with pre-existing psychotic illness, the airport environment can engender a delusional mood, a source of delusional thinking. ${ }^{14}$

Alcohol is often used to assuage fears associated with travel, and this in itself constitutes an important travel-associated mental health risk. ${ }^{15}$ The use of alcohol and drugs of abuse can elicit psychiatric symptoms and can aggravate dehydration, motion sickness, and temperature-related illness. ${ }^{16,17}$ The best known sequelae of alcohol-triggered mental disturbance during travel are loss of inhibition and explosive anger (i.e., air rage)..$^{18}$ The more psychologically compromised someone is prior to travel, the more susceptible that person is to substance-related decompensation during travel.

The use of one's own therapeutic drugs bears risks as well by increasing the danger of thrombosis and pulmonary embolism on long flights. ${ }^{19,20}$ Travelers may also suffer adverse effects from immunizations or prophylactic travel drugs, some of which are known to produce psychotic symptoms in some individuals. ${ }^{21}$ It has been estimated that 1 in 10000 to 15000 users of mefloquine (used for malaria prophylaxis when traveling to countries where malaria is endemic) suffers from neuropsychiatric reactions, which can last from a few minutes to several weeks. ${ }^{8,22}$ The reaction usually takes the form of confusion and disorientation. ${ }^{23}$ Routine antipsychotic drug regimens can cause skin reactions at destinations where the sun is unaccustomedly strong ${ }^{24}$ and such reactions can be misinterpreted in a delusional way. ${ }^{25}$ Any new symptom can act as a kernel for the formation of delusions in vulnerable individuals. $^{26}$

\section{Case Example: Travel Erotomania}

A patient who attended the women's Clinic for psychosis felt nauseous on the first leg of a journey by airplane. She developed the idea that the pilot was deliberately making her ill so that he would have an excuse to be with her when the plane landed. She was convinced that he had fallen instantaneously in love with her when he saw her board the plane.

Erotomania has been viewed as a delusion that fulfils an emotional need, ${ }^{27}$ a need for affection that is reinforced by the loneliness and apprehension of travel, a vulnerable state Klaus Conrad called das trema. ${ }^{26}$ In this state, an ill feeling can be easily misinterpreted in a self-referential fashion (e.g., "The pilot is making me sick on purpose.") The original physical sensation can suddenly acquire extraordinary significance (e.g., "This is uncanny") and, perhaps result in reasoning biases such as premature "jumping to conclusions"28 and believing oneself to be the center of attention of important others (the pilot). ${ }^{29}$

\section{Reaching One's Destination}

Certain specific travel destinations, such as the end points of pilgrimages or sites of personal significance to individuals, have historically been associated with transient, or sometimes more long-lasting, psychotic reactions such as the "Jerusalem syndrome." ${ }^{30-33}$ This phenomenon occurs when individuals identify with characters in holy texts or come to believe that they have a political or God-given mission that must be accomplished upon arrival at symbolically-weighted locations.

Because individuals with pre-existing psychotic illness rarely find the financial means to travel for recreation, when they do travel, it is most often for formal events such as weddings or funerals. The nature and meaning of the event, and especially the individuals they are exposed to, may be sufficient to trigger psychosis.

Case Example: Relapse Induced by Interpersonal Stress

A patient from the women's clinic whose illness was stable traveled with her husband and daughter to celebrate her mother-in-law's birthday in another town. She had not seen her mother-in-law since her first psychotic episode a decade earlier at which time the two women had bitterly quarreled. Barely into the visit, the patient began to re-experience psychotic symptoms.

Forced relationships with individuals encountered while traveling can trigger overwhelming social anxiety. Travel also entails unaccustomed accommodations that may provoke distress and fuel delusional thinking (e.g., "They are laughing at me. I can hear whispers through the wall.") Unfamiliar situations are well known for inducing paranoid thinking. ${ }^{34}$

An important stressor associated with travel is leaving behind one's emotional support system..$^{35-38}$ For mental health service users, this means not only separation from family and friends but also from trusted care providers and health resources. Broken attachments include places as well as people. ${ }^{39,40}$ Travel dramatically disturbs both animate and inanimate worlds, and individuals who have left home feel not only the loss of significant others, but also of the sights, sounds, smells, customs, and social milieu of familiar surroundings. Without emotional anchors such as one's own language, monetary system, transportation system, or shopping procedures, culture shock and disorientation can easily ensue. The loss of a familiar environment can be as distressing as the loss of a person, leading, by a similar trajectory, to homesickness, nostalgia, and a sense of diminished belonging. ${ }^{41}$ It is not unusual for an unfamiliar place to be perceived as hostile and threatening, especially if one is vulnerable to the misinterpretation of sensory perceptions. ${ }^{34}$ Marcheschi et $\mathrm{al}^{42}$ found that, in people with severe mental illness living in supported housing, perceived physical and social factors in their environments determined approximately one third of the variance in the quality of their lives. The loss of a habitual social or occupational role while traveling (even the often stigmatized role of psychiatric patient) can lead to a sense of rootlessness and lost identity, ${ }^{43}$ which looms especially large for individuals with personal experience of psychosis. Changes in temperature, climate, sunlight, or altitude also contribute to feelings of dislocation that lead, initially, to somatic discomfort. When the landscape also changes and familiar objects and rituals disappear, vulnerable individuals may subsequently experience fear that leads to misinterpretations of the inner (hallucinations) and outer (delusions) environment.

Like stress of any kind, acculturative stress increases the risk 
for psychosis. ${ }^{44}$ One form of acculturative stress is the fear of getting the language or customs of another country wrong and being laughed at. ${ }^{45,46}$ Individuals such as those with mental illness who have previously been exposed to stigmatizing attitudes are especially vulnerable to perceived ridicule and loss of face. ${ }^{47}$

\section{Post Travel Jet Lag}

Reports in the literature have frequently noted an association between lack of sleep and emotional distress. ${ }^{48}$ Insomnia is aggravated by long distance travel and jet lag, which can trigger psychotic relapse. This association was first reported in $1959,{ }^{49}$ with many more reports appearing since. ${ }^{23,50-54}$

Jet lag is thought to exacerbate psychotic conditions by disrupting the biological circadian system, and, in very vulnerable individuals, it can even precipitate de novo psychosis. $^{51,52}$ Jet lag is associated with the greatest risk when multiple time zones are crossed in the same journey. The severity and extent of the physical, neurological, and emotional symptoms associated with jet lag also depend on the direction and speed of travel. It is easier to adjust to a longer day than to a shorter one, so that travel westward elicits less pronounced jet lag. ${ }^{55}$ On average, the rate of adaptation is approximately half a day per hour of time difference westwards, and 1 day per hour of the time difference eastwards. ${ }^{56}$ In individuals with prior mental illness, circadian rhythms may already be disrupted ${ }^{57}$; research has linked polymorphisms or dysregulations of clock genes to schizophrenia. ${ }^{58,59}$ One cause (or effect) is the quasi-nocturnal lifestyle led by many individuals with schizophrenia, which contributes to a limited exposure to light. It also limits exposure to social zeitgebers, which are interpersonal events that regulate circadian rhythms and synchronize them with the environment. ${ }^{60}$ Circadian disruption, sleep onset insomnia, and difficulties in maintaining sleep in patients with schizophrenia may also be related to deficits in melatonin, leading to overactivity of the dopamine system. Melatonin deficits also result in dysfunction of the gamma-aminobutyric acid (GABA)-ergic system involved in sleep-wake signaling. ${ }^{61}$

\section{Who Is Most Vulnerable?}

Increasing age is associated with increasing neurological and sensory vulnerability. This means that the elderly have a lower risk threshold for the stresses of travel..$^{62}$ Disrupted circadian rhythms are slower to recover in older age and are thus more likely to lead to psychiatric symptoms. ${ }^{63}$

Women are more susceptible than men to both the motion sickness of travel by sea, ${ }^{64}$ and to the desynchronization of body rhythms in jet lag syndromes. The latter disrupt cyclical hormonal patterns and, in this way, lower the threshold for psychotic manifestations. ${ }^{65}$ The literature on gender differences in circadian patterns in young and older adults is, however, conflicting, because not all studies have controlled for the effects of age. ${ }^{66}$

\section{Preventing Travel-Related Psychiatric Problems \\ Practical Issues \\ Careful pre-travel screening and preparation can obviate many problems, ${ }^{67}$ and have proven to be effective. ${ }^{68}$ \\ Individuals with pre-existing psychotic conditions are usually}

not expert travelers and often need guidance with respect to passports, visas, and pre-travel immunizations. ${ }^{69}$ They may need help with a number of practical planning issues such as choice of luggage, appropriate clothing for the intended destination, and adapters for electronic devices. Novice travelers may need information about what can and cannot be brought on board airplanes and what will be required during airport screening. Patients who receive monthly disability payments will need to organize a bridging arrangement to cover the period of travel. Patients should be advised to obtain sufficient cash and travelers' checks or an ATM card in advance and to purchase a pocket travel dictionary of useful phrases in the language of the host country. Medical insurance coverage for travel and for the stay in the country of destination also needs to be pre-arranged. For potentially unstable patients, medical insurance that covers the cost of hospital treatment in a foreign country and the cost of potential repatriation needs to be in place. ${ }^{70}$

\section{Medications and Medical Care}

Travelers should have with them copies of all their prescriptions. Explanatory letters from physicians may also be helpful because some countries have been known to refuse entry to travelers with a history of psychosis. All documents should be understandable in the different countries of transit and destination (e.g., such records should use generic names of medications). Patients should be advised to pack necessities such as medications in a carry-on bag in case checked luggage arrival is delayed.

It is advisable for care providers to liaise with providers at the destination site so that travelers have easy access to psychiatric care should it prove necessary. For individuals who receive depot antipsychotic injections, arrangements will need to be made for receipt of the injection at an appropriate site. Arrangements also need to be made for monitoring blood tests for patients being treated with clozapine or lithium. Clozapine is usually dispensed in amounts that cover only the period between blood tests; it is critical to cover the whole travel period because interruption of clozapine can lead to rapid relapse. ${ }^{71}$

Anticipating travel stress, rehearsing responses to potential stressors, and practicing relaxation and breathing exercises are all helpful preparatory interventions. It can be useful to provide literature about the problems of jet lag or sea sickness, ${ }^{72}$ to recommend, for instance, adequate sleep prior to travel, a ship cabin at water level or an airplane seat over the wings. ${ }^{73}$ Frequent consumption of light, soft, bland, low-fat, and low-acid food can minimize symptoms of motion sickness. For individuals who are more than usually prone to nausea, medications such as scopolamine can be prescribed. They are most effective when taken ahead of time although they may cause side effects (e.g., blurred vision, drowsiness, dry mouth) about which patients should be informed. ${ }^{73}$ Antacids can be helpful for stomach upset. ${ }^{73}$ Breathing exercises, regular stretches, abstinence from alcohol and plentiful fluid intake (not caffeinated) minimize the dehydrating effects of flight. It may be helpful to advise patients to bring books and magazines to read because sharing a close space with unfamiliar persons during a long airplane flight may prove intensely stressful. ${ }^{74}$ 


\section{Police Records}

Patients with a police record (e.g., individuals who have been brought to hospital by police for psychiatric assessment at some point in the past) need to ascertain whether this will block access to their country of destination. It is important for such patients to know that old police records can be sealed or expunged upon request. ${ }^{75}$

Case Example: Being Stopped at the Border

One Canadian patient, wanting to visit her parents who lived across the border in the United States, was turned back because she had once called the police, many years earlier, thinking she was being attacked. The call had resulted in a hospitalization with a subsequent police record of which she had not been aware.

\section{Upon Arrival}

Light is known to be the most important entrainer of circadian rhythm. When flying west, exposure to bright light in the evening and avoidance of light in the morning (e.g., by using eye shades or dark glasses) is recommended to induce a phase delay and, thus, minimize jet lag. When flying east, exposure to light in the morning and avoidance of light in the evening induce a circadian phase advance. ${ }^{4}$ The $\mathrm{WHO}^{4}$ recommends a minimum block of 4 hours of sleep during the local nightknown as "anchor sleep" - to adapt to the new time zone. Day naps (with eye shades and earplugs) may help; a short nap upon arrival is especially strategic if feasible. Short-acting hypnotics may help with insomnia. WHO also recommends avoiding strenuous exercise during the 2 hours before attempting sleep; otherwise exercise, food consumption, and the taking of medication need to be adapted to the local time. Alertness-enhancing drugs (e.g., coffee, modafinil) are not recommended for individuals with pre-existing psychotic illness. ${ }^{4}$

Melatonin is a chronobiotic (able to change the hands on the circadian clock) that is secreted by the pineal gland and turned off by light. It is available commercially in some countries, but WHO cautions that manufacturing methods are not standardized across the world. ${ }^{4}$ A Cochrane Review found that melatonin was effective in countering the effects of jet lag and was safe for short-term use (for up to 4 days after arrival at one's destination). The recommended dose is 2 to $5 \mathrm{mg}$ taken 2 to 3 hours before bedtime. No evidence of benefit has been found when melatonin is taken prior to travel, however. ${ }^{76}$ Melatonin reduces the latency of sleep onset, increases sleep efficiency, and increases sleep duration. ${ }^{77}$ It may also have antidepressant effects, ${ }^{78}$ useful in vulnerable populations.

\section{Discussion}

Travel, even when embarked on for the purpose of relaxation and enjoyment, can prove so stressful for individuals with pre-existing severe mental illness that it can result in psychotic relapse. Susceptible individuals adapt poorly to stressors and initial maladaptive responses can lead to more persistent forms of illness. ${ }^{79}$ Unpredictability of the stress is an important mediating factor; a stressor that is unexpected is especially difficult to adapt to and usually has relatively more severe consequences for the person. One hypothesis is that persons with serious mental illness are particularly

\section{Review Highlights}

\section{What Is Already Known?}

It is well known that stress, insomnia, substance use, jet lag, and specific destinations can provoke psychotic reactions in vulnerable individuals.

\section{What This Study Adds?}

This review elaborates on the stresses of travel, adding unfamiliarity, loss of support, physical discomfort, new drugs, and interrupted medication schedules into the mix of psychotogenic risk factors. It also makes recommendations on how these can be avoided.

stressed by events that they perceive as uncontrollable and that are seen as threats. Such events can leave a person feeling victimized, exploited, and powerless. ${ }^{80}$ Sudden losses have also been shown to lead to considerable subjective distress in this population. ${ }^{81}$ Travel often presents with unpredicted contingencies and with situations in which people can easily feel that they have lost their moorings and their ability to control what happens next. Many problems of travel can, however, be anticipated, thus markedly reducing the sense of loss and powerlessness.

Individuals differ in their susceptibility to stressors and this includes travel stress. The hypothalamic pituitary adrenal axis in women differs from that of men, rendering women more susceptible than men because of stronger and more prolonged secretion of steroids in response to stress. ${ }^{79}$

\section{Conclusion}

Travel is a life event that carries potential risk for individuals with prior mental illness, especially for the elderly and for women. As long as the risks are recognized and anticipated, most stressors encountered during travel can be prepared for in advance and obviated.

\section{Conflict of Interest Disclosures}

No conflict of interest.

\section{Ethical Approval}

This review did not require institutional ethics approval.

\section{Funding/Support}

This review received no funding or external support.

\section{Acknowledgments}

The author thanks the members of the Women's Clinic for Psychosis.

\section{References}

1. Beards S, Gayer-Anderson C, Borges S, Dewey ME, Fisher HL, Morgan C. Life events and psychosis: a review and meta-analysis. Schizophr Bull. 2013;39(4):740-747. doi:10.1093/schbul/sbt065

2. Flinn DE. Transient psychotic reactions during travel. Am J Psychiatry. 1962;119(2):173-174. doi:10.1176/ajp.119.2.173

3. Miller WB, Zarcone V. Psychiatric behavior disorders at an international airport. Arch Environ Health. 1968;17(3):360-365.

4. World Health Organization (WHO). International travel and health. Psychological health. General considerations. Geneva, Switzerland: WHO, 2016. http://www.who.int/ith/other_health_ 
risks/psychological_health/en/. Accessed July 23, 2016.

5. Felkai P, Kurimay T. The most vulnerable travelers: patients with mental disorders. World Psychiatry. 2011;10(3):237. doi:10.1002/j.2051-5545.2011.tb00063.x

6. Vermersch C, Geoffroy PA, Fovet T, Thomas P, Amad A. [Travel and psychotic disorders: clinical aspects and practical recommendations]. Presse Med 2014;43(12 Pt 1):1317-1324. doi:10.1016/j.Ipm.2014.05.010

7. Zittoun C, Recasens C, Dantchev N. [Psychopathology and travel: psychiatric patient repatriation]. Ann Med Psychol (Paris). 1994;152(10):696-700.

8. Beny A, Paz A, Potasman I. Psychiatric problems in returning travellers: features and associations. J Travel Med. 2001;8(5):243246. doi:10.2310/7060.2001.24019.

9. Caro F. [Pathological displacement: background and differential diagnoses]. L'information Psychiatrique. 2006;82(5):405-514. doi:10.3917/inpsy.8205.0405.

10. Seeman MV, Cohen R. A service for women with schizophrenia. Psychiatr Serv. 1998;49(5):674-677. doi:10.1176/ps.49.5.674.

11. Hopper K. Symptoms, survival, and the redefinition of public space: a feasibility study of homeless people at a metropolitan airport. Urban Anthropol Stud Cult Syst World Econ Dev. 1991:20(2):155-175.

12. Shapiro $S$. Airport wandering as a psychotic symptom. Psychiatrica Clinica (Basel). 1982;15(4):173-176.

13. Shapiro S. A study of psychiatric syndromes manifested at an international airport. Compr Psychiatry. 1976;17(3):453-456.

14. Fuchs T. Delusional mood and delusional perception -- a phenomenological analysis. Psychopathol. 2005;38(3):133-139. doi:10.1159/000085843.

15. Lange WR, McCune BA. Substance abuse and international travel. Adv Alcohol Subst Abuse. 1989;8(2):37-51. doi:10.1300/ J251v08n02_02.

16. Mirabile CS Jr, Glueck BC. Motion sickness susceptibility patterns of psychotic illness. Arch Gen Psychiatry. 1980;37(1):42-46. doi:10.1001/archpsyc.1980.01780140044005.

17. Thomas DR, Cote TR, Lawhorne $L$, et al. Understanding clinical dehydration and its treatment. J Am Med Dir Assoc. 2008;9(5):292301. doi:10.1016/j.jamda.2008.03.006.

18. Anglin L, Neves P, Giesbrecht N, et al. Alcohol-related air rage: from damage control to primary prevention. J Prim Prev. 2003;23(3):283-297. doi:10.1023/A:1021341707993.

19. Wu CS, Lin CC, Chang CM, et al. Antipsychotic treatment and the occurrence of venous thromboembolism: a 10-year nationwide registry study. J Clin Psychiatry. 2013;74(9):918-924. doi:10.4088/ JCP. $12 \mathrm{~m} 08117$

20. Allenet B, Schmidlin S, Genty C, Bosson JL. Antipsychotic drugs and risk of pulmonary embolism. Pharmacoepidemiol Drug Saf. 2012;21(1):42-48. doi:10.1002/pds.2210.

21. Schneider C, Adamcova M, Jick SS, et al. Antimalarial chemoprophylaxis and the risk of neuropsychiatric disorders. Travel Med Infect Dis. 2013;11(2):71-80. doi:10.1016/j. tmaid.2013.02.008.

22. Fuller SJ, Naraqi S, Gilessi G. Paranoid psychosis related to mefloquine antimalarial prophylaxis. Papua New Guinea Med J. 2002;45(3-4):219-221.

23. Habib AG, Tambyah PA. Confusion in travelers. Travel Med Infect Dis. 2004;2(1):23-25. doi:10.1016/j.tmaid.2004.01.003.

24. Bliss SA, Warnock JK. Psychiatric medications: adverse cutaneous drug reactions. Clin Dermatol. 2013;31(1):101-109. doi:10.1016/j. clindermatol.2011.11.014.

25. Potasman I, Beny A, Seligmann H. Neuropsychiatric problems in 2500 long-term young travelers to the tropics. J Travel Med. 2000;7(1):5-9. doi:10.2310/7060.2000.00002.

26. Mishara AL. Klaus Conrad (1905-1961): delusional mood, psychosis, and beginning schizophrenia. Schizophr Bull. 2010;36(1):9-13. doi:10.1093/schbul/sbp144

27. Seeman MV. Erotomania and recommendations for treatment. Psychiatr Quart. 2016;87(2):355-364. doi:10.1007/s11126-0159392-0.

28. Fine C, Gardner M, Craigie J, Gold I. Hopping, skipping or jumping to conclusions? Clarifying the role of the JTC bias in delusions. Cogn Neuropsychiatry. 2007;12(1):46-77. doi:10.1080/13546800600750597.

29. Davidson L, Stayner D. Loss, loneliness, and the desire for love: perspectives on the social lives of people with schizophrenia. Psychiatr Rehabil J. 1997;20(3):3-12. doi:10.1037/h0095369.

30. Bar-El Y, Durst R, Katz G. Jerusalem syndrome. Br J Psychiatry. 2000;176(1):86-90. doi:10.1192/bjp.176.1.86.

31. Eytan A, Favre S, Gex-Fabry M, Borras L, Ferrero F, Bertschy G. Pathological journeys or help seeking behavior: the case of travelers to Geneva, an international city. Open Psychiatry J. 2007;1:26-30.

32. Poleszczyk A, Święcicki Ł. [Jerusalem syndrome - a case report]. Psychiatr Pol. 2013;47(2):353-360.

33. Wirtzum E, Kalian M. The "Jerusalem syndrome"--fantasy and reality a survey of accounts from the 19th century to the end of the second millennium. Isr J Psychiatry Relat Sci. 1999;36(4):260-271.

34. Freeman D, Emsley R, Dunn G, et al. The stress of the street for patients with persecutory delusions: a test of the symptomatic and psychological effects of going outside into a busy urban area. Schizophr Bull. 2015;41(45):971-979. doi:10.1093/schbul/ sbu173.

35. Ainsworth MDS. Attachments across the life-span. Bull NY Acad Med. 1985;61(9):792-812.

36. Bowlby J. Attachment and Loss, Vol.1, 2nd ed. New York: Basic Books; 1982.

37. Manicavasagar V, Silove D, Curtis J. Separation anxiety in adulthood: a phenomenological investigation. Compr Psychiatry. 1997;38(5):274-282. doi:10.1016/S0010-440X(97)90060-2.

38. Marnane C, Silove D. DSM-5 allows separation anxiety disorder to grow up. Aust N Z J Psychiatry. 2013;47(1):12-15. doi:10.1177/0004867412461285.

39. Weiss RS. Attachment in adult life. In: Parkes CM, Stevenson-Hind J, eds. The Place of Attachment in Human Behaviour. New York: Basic Books; 1982.

40. Burnham DL. Separation anxiety: a factor in the object relations of schizophrenic patients. Arch Gen Psychiatry. 1965;13(4):346-358. doi:10.1001/archpsyc.1965.01730040056009.

41. Ogden LP. Interpersonal relationship narratives of older adults with schizophrenia-spectrum diagnoses. Am J Orthopsychiatry. 2014;84(6):674-84. doi:10.1037/ort0000035.

42. Marcheschi E, Laike T, Brunt D, Hansson L. Quality of life and place attachment among people with severe mental illness. J Environ Psychol. 2015;41:145-54. doi:10.1016/j.jenvp.2014.12.003.

43. Blank AA, Harries P, Reynolds F. 'Without occupation you don't exist': occupational engagement and mental illness. J Occupational Sci. 2015;22(2):197-209. doi:10.1080/14427591.2014.882250.

44. van Winkel R, Stefanis NC, Myin-Germeys I. Psychosocial stress and psychosis. A review of the neurobiological mechanisms and the evidence for gene-stress interaction. Schizophr Bull. 2008;34(6):1095-105. doi:10.1093/schbul/sbn101.

45. Platt T, Ruch W, Hofmann J, Proyer RT. Extreme fear of being laughed at: components of gelotophobia. Isr J Humor Res Intern J. 2012;1(1):86-106.

46. Ruch W, Hofmann J, Platt T, Proyer R. The state-of-the art in gelotophobia research: a review and some theoretical extensions. Humor. 2014;27(1):23-45. doi:10.1515/humor-2013-0046.

47. Ruch W, Hofmann J, Platt T. Individual differences in gelotophobia and responses to laughter-eliciting emotions. Personality Individ Diff. 2015;72:117-21. doi:10.1016/j.paid.2014.08.034.

48. Seixas AA, Nunes JV, Airhihenbuwa CO, et al. Linking emotional distress to unhealthy sleep duration: analysis of the 2009 National Health Interview Survey. Neuropsychiatr Dis Treat. 2015;11:242530. doi:10.2147/NDT.S77909.

49. Flinn DE, Gaarder KR, Smith DC. Acute psychotic reactions during travel. US Armed Forces Med J. 1959;10(5):524-531.

50. Brennan E, Kulkarni J. Travel advice for patients with psychotic disorders. Aust N Z J Psychiatry. 2014;48(7):687. doi:10.1177/0004867413520051.

51. Katz G. Jet lag and psychotic disorders. Curr Psychiatry Rep 2011;13(3):187-92. doi:10.1007/s11920-011-0192-4.

52. Perrier E, Manen O. [Jet lag disorders]. Rev Med Interne. 2011;32(Suppl 2):S233-S235. doi:10.1016/j.revmed.2011.09.010.

53. Sack RL. Jet lag. N Eng J Med. 2010;362(5):440-7. doi:10.1056/ 
NEJMcp0909838.

54. Vanelle JM. [Schizophrenia and circadian rhythms]. Encephale. 2009;35(Suppl 2):S803. doi:10.1016/S0013-7006(09)75540-X.

55. Reilly T, Waterhouse J, Edwards B. Some chronobiological and physiological problems associated with long-distance journeys. Travel Med Infect Dis. 2009;7(2):88-101. doi:10.1016/j. tmaid.2008.05.002.

56. Sack RL. The pathophysiology of jet lag. Travel Med Infect Dis. 2009;7(2):102-110. doi:10.1016/j.tmaid.2009.01.006.

57. Wulff K, Dijk DJ, Middleton B, Foster RG, Joyce EM. Sleep and circadian rhythm disruption in schizophrenia. Br J Psychiatry. 2012;200(4):308-316. doi:10.1192/bjp.bp.111.096321.

58. Mansour HA, Wood J, Logue T, et al. Association study of eight circadian genes with bipolar I disorder, schizoaffective disorder and schizophrenia. Genes Brain Behav. 2006;5(2):150-157. doi:10.1111/j.1601-183X.2005.00147.x.

59. Takao T, Tachikawa H, Kawanishi Y, Mizukami K, Asada T. CLOCK gene T3111C polymorphism is associated with Japanese schizophrenics: a preliminary study. Eur Neuropsychopharmacol. 2007;17(4):273-276. doi:10.1016/j.euroneuro.2006.09.002.

60. Mistlberger RE, Skene DJ. Social influences on mammalian circadian rhythms: animal and human studies. Biol Rev Camb Philos Soc. 2004;79(3):533-556. doi:10.1017/S1464793103006353.

61. Monti JM, BaHammam AS, Pandi-Perumal SR, et al. Sleep and circadian rhythm dysregulation in schizophrenia. Prog Neuropsychopharmacol Biol Psychiatry. 2013;43:209-216. doi:10.1016/j.pnpbp.2012.12.021.

62. Linton C, Warner NJ. Travel-induced psychosis in the elderly. Int J Geriatr Psychiatry. 2000;15(11):1070-1072.

63. Martin JL, Jeste DV, Ancoli-Israel S. Older schizophrenia patients have more disrupted sleep and circadian rhythms than agematched comparison subjects. J Psychiatr Res. 2005;39(3):251259. doi:10.1016/j.jpsychires.2004.08.011.

64. Flanagan MB, May JG, Dobie TG. Sex differences in tolerance to visually-induced motion sickness. Aviat Space Environ Med. 2005;76(7):642-646.

65. Mahoney MM. Shift work, jet lag, and female reproduction. Int J Endocrinol. 2010;2010:813764. doi:10.1155/2010/813764.

66. Thomas SJ, Lichstein KL, Taylor DJ, Riedel BW, Bush AJ. Epidemiology of bedtime, arising time, and time in bed: analysis of age, gender, and ethnicity. Behav Sleep Med. 2014;12(3):169182. doi:10.1080/15402002.2013.778202.

67. Fenner P. Fitness to travel - assessment in the elderly and medically impaired. Aust Fam Physician. 2007;36(5):312-315.

68. Tafuri S, Guerra R, Gallone MS, et al. Effectiveness of pre-travel consultation in the prevention of travel-related diseases: a retrospective cohort study. Travel Med Infect Dis. 2014;12(6 Pt B):745-749. doi:10.1016/j.tmaid.2014.10.012.
69. Roupa Z, Zikos D, Vasilopoulos A, Diomidous M. Common health risks, required precautions of travelers and their customs towards the use of travel medicine services. Mater Sociomed. 2012;24(2):131-134. doi:10.5455/msm.2012.24.131-134.

70. Stoney RJ. Travel insurance, travel health insurance, and medical evacuation insurance. Centers for Disease Control and Prevention, Health Information for International Travel 2016: The Yellow Book. http://wwwnc.cdc.gov/travel/yellowbook/2014/chapter-2-the-pretravel-consultation/travel-insurance-travel-health-insurance-andmedical-evacuation-insurance. Accessed July 23, 2016.

71. Seeman P, Tallerico T. Rapid release of antipsychotic drugs from dopamine D2 receptors: an explanation for low receptor occupancy and early clinical relapse upon withdrawal of clozapine or quetiapine. Am J Psychiatry. 1999;156(6):876-884. doi:10.1176/ajp.156.6.876.

72. Forbes-Robertson S, Dudley E, Vadgama P, Cook C, Drawer S, Kilduff L. Circadian disruption and remedial interventions: effects and interventions for jet lag for athletic peak performance: circadian disruption and remedial interventions. Sports Med. 2012;42(3):185-208. doi:10.2165/11596850-000000000-00000.

73. Brainard A, Gresham C. Prevention and treatment of motion sickness. Am Fam Physician. 2014;90(1):41-46.

74. Boydell KM, Gladstone BM, Crawford ES. The dialectic of friendship for people with psychiatric disabilities. Psychiatr Rehabil J. 2002;26(2):123-131. doi:10.2975/26.2002.123.131.

75. Kilgour L. Tracing the lifecycle of Canadian criminal records: a critical examination in relation to public policy and user access and comprehension. Rec Manag J. 2013;23:136-148.

76. Herxheimer A, Petrie KJ. Melatonin for the prevention and treatment of jet lag. Cochrane Database Syst Rev. 2002;(2):CD001520. doi:10.1002/14651858.CD001520.

77. Brzezinski A, Vangel MG, Wurtman RJ, et al. Effects of exogenous melatonin on sleep: a meta-analysis. Sleep Med Rev. 2005;9(1):4150. doi:10.1016/j.smrv.2004.06.004.

78. Srinivasan V, De Berardis D, Shillcut SD, Brzezinski A. Role of melatonin in mood disorders and the antidepressant effects of agomelatine. Expert Opin Investig Drugs. 2012;21(10):15031522. doi:10.1517/13543784.2012.711314.

79. Franklin TB, Saab BJ, Mansuy IM. Neural mechanisms of stress resilience and vulnerability. Neuron. 2012;75(5):747-761. doi:10.1016/j.neuron.2012.08.016.

80. Jones SR, Fernyhough C. A new look at the neural diathesis-stress model of schizophrenia: the primacy of social-evaluative and uncontrollable situations. Schizophr Bull. 2007;33(5):1171-1177. doi:10.1093/schbul/sbl058.

81. O'Hare T, Sherrer M. Subjective distress associated with sudden loss in clients with severe mental illness. Comm Ment Health J. 2011;47(6):646-653. doi:10.1007/s10597-011-9382-0. 